\title{
Avaliação das tecnologias pós-colheita utilizadas e da qualidade de melões nobres produzidos para exportação
}

\author{
Evaluation of the postharvest technologies used and quality of noble melons produced for exportation
}

\author{
Patrícia Lígia Dantas MORAIS ${ }^{1 \star}$, Geomar Galdino da SILVA ${ }^{1,2}$, \\ Emanuel Nogueira MAIA², Josivan Barbosa MENEZES ${ }^{2}$
}

\section{Resumo}

O presente estudo teve como objetivo avaliar as tecnologias pós-colheita utilizadas e a qualidade dos frutos produzidos nas fazendas exportadoras de melões nobres, situadas no Polo Agrícola Mossoró-Assu/RN. Foram estudados os melões Gália 'Solar King', Cantaloupe 'Torreon', Charentais 'Aura Prince’ e Orange Flesh 'AF-1749', quanto às seguinte variáveis de qualidade: perda de massa, aparências interna e externa, firmeza da polpa, acidez titulável, $\mathrm{pH}$, sólidos solúveis e açúcares. Os frutos foram avaliados aos 0, 7, 14, 21 e 28 dias de armazenamento refrigerado. O período de transporte foi simulado, armazenando os frutos nas mesmas condições de temperatura e umidade relativa em que são transportados. Conclui-se que as empresas produtoras e exportadoras de melões nobres utilizam um alto nível de tecnologia pós-colheita para manter a qualidade dos frutos dessas cultivares que apresentam pouca resistência pós-colheita. No entanto, foi constatado, pelos altos valores de firmeza e baixos de sólidos solúveis, que são colhidos frutos ainda imaturos. Na avaliação das aparências externa e interna, foi observado, aos 28 dias, que os frutos ainda estavam comercializáveis, apesar de terem atingido a nota limite devido ao aparecimento de defeitos, tais como, manchas, depressões e injúrias, que podem ser reduzidos com o manejo mais adequado dos frutos.

Palavras-chave: Cucumis melo; armazenamento; mercado externo; vida útil pós-colheita.

\begin{abstract}
The present study aimed to evaluate postharvest technologies and quality of fruits produced on noble melons exporting farms located in the Agricultural Pole Mossoró-Assu, in the state of Rio Grande do Norte, Brazil. Gália 'Solar King', Cantalaupe 'Torreon', Charentais 'Aura Prince', and Orange Flesh 'AF-1749' melons were analyzed regarding the following quality aspects: loss of weight, internal and external appearance, firmness, titulable acidity, $\mathrm{pH}$, soluble solids, and sugars. The fruits were evaluated on the $0,7^{\text {th }}, 14^{\text {th }}, 21^{\text {th }}$, and $28^{\text {th }}$ day of storage refrigeration. The period of transport was simulated by storing the fruits under the same conditions of temperature and relative humidity of transport. It was concluded that the melons exporting farms use high level postharvest technological to maintain the fruit quality of these melon cultivare which present low postharvest resistance. However, it was noted by the high firmness and low of soluble solid values that the fruits are harvested when still immature. During the evaluation of external and internal appearance, it was observed that on the $28^{\text {th }}$ day the fruits could still be commercialized although reaching the acceptance limit due to some flaws such as spots, depressions, and damage which can be reduced with a more appropriate fruit handling.
\end{abstract}

Keywords: Cucumis melo; storage; external market; postharvest shelf life.

\section{Introdução}

$\mathrm{Na}$ economia do Estado do Rio Grande do Norte, a fruticultura é o principal item do seu agronegócio. Entre as frutas exportadas por este Estado, destaca-se o melão, que lhe tem proporcionado a liderança no ranking dos Estados produtores do Brasil. As exportações de melão movimentam um volume de recursos na ordem de US\$ 64 milhões. O setor também é um dos grandes geradores de emprego em Mossoró (RN) e região. De acordo com o Comitê Executivo de Fitossanidade do Rio Grande do Norte (COEX) atualmente, a fruticultura irrigada gera 24 mil empregos diretos e outros $60 \mathrm{mil} \mathrm{de} \mathrm{forma} \mathrm{indireta}$ (ALBUQUERQUE, 2008).

Apesar do crescimento nas exportações de melões nos últimos anos no Estado do Rio Grande do Norte, ainda se tem observado a chegada de melões com a qualidade comprometida nos países importadores. Moura (2003) verificou que a qualidade dos melões exportados pelo porto de Natal-RN no ano de 2003 apresentou um baixo nível tecnológico utilizado pelas empresas regionais, pois foi observado que apenas $53,5 \%$ das empresas produziram melóes com teor de sólidos solúveis igual ou superior ao exigido pelos mercados importadores e, somente, $36,4 \%$ conseguiram atingir o índice de firmeza de polpa exigido para o melão.

O objetivo do presente trabalho foi avaliar as tecnologias pós-colheita utilizadas e a qualidade dos frutos produzidos nas fazendas exportadoras de melóes nobres, situadas no Polo Agrícola Mossoró-Assu/RN.

Recebido para publicação em 10/9/2007

Aceito para publicação em 3/1/2009 (002840)

${ }^{1}$ Ciências Vegetais, Universidade Federal Rural do Semi-Árido, Mossoró - RN, Brasil, E-mail: plmorais@hotmail.com

${ }^{2}$ Departamento de Ciências Ambientais, Universidade Federal Rural do Semi-Árido - UFERSA, CEP 59625-900, Mossoró - RN, Brasil

${ }^{*}$ A quem a correspondência deve ser enviada 


\section{Material e métodos}

A pesquisa teve início com visitas às principais fazendas produtoras de melão do Polo Agrícola Mossoró-Assu/RN, onde foram utilizados questionários e feitas observações detalhadas a fim de se obter informações acerca das tecnologias póscolheita empregadas. Também foram coletadas, para avaliação da qualidade dos frutos, amostras das caixas de melões nobres que estavam prontas para serem transportadas para o mercado externo, ou seja, após passar por todos os procedimentos e tratamentos pós-colheita utilizados nos packing house das fazendas. Foram coletadas amostras das seguintes cultivares de melões nobres: Gália 'Solar King', Cantaloupe 'Torreon', Charentais 'Aura Prince' e Orange flesh 'AF-1749'. Em seguida, as caixas de melões coletadas foram avaliadas e outra parte armazenada nas câmaras de refrigeração da empresa nas mesmas condições de temperatura e umidade relativa em que são transportadas para os países de destino. Uma vez na semana $(0,7,14,21$ e 28 dias de armazenamento refrigerado), foi retirada uma amostra dos frutos armazenados e transportada para o Laboratório de Pós-colheita da UFERSA, onde foram avaliados quanto aos atributos de qualidade. Foram realizadas nos melões as seguintes avaliações:

Espessura da polpa $(\mathrm{cm})$ - os melões foram divididos longitudinalmente em duas partes e, em cada metade, a espessura da polpa foi medida com o auxílio de um paquímetro digital. Comprimento longitudinal e transversal - foi também medido em cada metade do melão com um paquímetro digital. Relação de formato - foi obtida dividindo o diâmetro longitudinal pelo transversal do fruto. Perda de massa (\%) - foi determinada por meio da massa individual dos frutos, no dia da colheita e na data da avaliação, utilizando-se balança semianalítica. Firmeza (N) foi determinada utilizando-se um penetrômetro com ponteira de $6 \mathrm{~mm}$ de diâmetro: o fruto foi dividido longitudinalmente em duas partes e, em cada metade, foram realizadas duas medições (uma em cada lado da região equatorial da polpa). Acidez titulável - foi obtida por titulação do suco com solução de $\mathrm{NaOH}$ 0,1 N e expressa como percentagem de ácido cítrico, segundo metodologia do Instituto Adolfo Lutz (1985). pH - foi determinado em potenciômetro digital com membrana de vidro, conforme Association of Official Analytical Chemists (2002). Sólidos solúveis (\%) - foram determinados no suco, utilizando-se um refratômetro digital com correção automática de temperatura (escala de 0 a 32\%). Açúcares totais (\%) - foram determinados por meio do método redutométrico de Yemn e Willis (1954). Aparência externa e interna - foi avaliada por meio de escala adaptada por Menezes (1996), considerando ausência ou presença de depressões, manchas escuras, murchamentos e ataque de patógenos. Para a aparência interna, foi observada a existência de sementes soltas e de líquido na cavidade do fruto, colapso interno e injúria pelo frio. A escala subjetiva correspondeu a notas de acordo com a severidade dos defeitos: 1 - extremamente severo (mais de $50 \%$ do fruto afetado); 2 - severo (50 a 31\% do fruto afetado); 3 - moderado (30 a $11 \%$ do fruto afetado); 4 - leve (10 a 1\% do fruto afetado), 5 - ausente (menos de $1 \%$ afetado). Foram considerados como frutos inadequados para comercialização aqueles cujas notas apresentaram valores inferiores a 3,0 para quaisquer avaliações.

$\mathrm{Na}$ avaliação das tecnologias pós-colheita utilizadas, foi realizada uma análise descritiva dos questionários e observa- ções feitas durantes as visitas. Já, para a avaliação da qualidade dos frutos, foi instalado um experimento em delineamento inteiramente casualizado, no qual os tratamentos foram os tempos de armazenamento, ou seja, 0, 7, 14, 21 e 28 dias, com cinco repetições compostas de um fruto por parcela. Os frutos foram mantidos por 28 dias à temperatura de $9{ }^{\circ} \mathrm{C} \pm 2{ }^{\circ} \mathrm{C} \mathrm{e}$ umidade relativa de $80 \% \pm 5 \%$, com exceção do melão Cantaloupe 'Torreon' que foi armazenado a $3{ }^{\circ} \mathrm{C} \pm 2{ }^{\circ} \mathrm{C}$ e umidade relativa de $80 \% \pm 5 \%$. Para os melões Cantaloupe 'Torreon' e Charentais 'Aura Prince', foi utilizada atmosfera modifica com bolsas poliméricas Xtend ${ }^{\circledast}$ dentro das caixas.

\section{Resultados e discussão}

\subsection{Tecnologias pós-colheita utilizadas para manter a qualidade dos melões nobres}

Segundo os resultados obtidos nos questionários e observações detalhadas, foi observado que, durante o manejo póscolheita, desde a colheita até a comercialização, são utilizados nos melões os procedimento e tecnologias relatadas abaixo.

A pré-seleção dos frutos ocorre ainda no campo e na recepção dos frutos no galpão. Os melões são selecionados descartando-se aqueles que apresentem defeitos visíveis na casca, tais como: ranhuras, cicatrizes, danos mecânicos, além de má formação, sintomas de patogenias como manchas de viroses e outros aspectos indesejáveis. A classificação se dá pelo calibre do fruto.

No galpão de embalagem, os frutos são recebidos de acordo com o tratamento pós-colheita destinado a cada variedade. No caso do Cantaloupe 'Torreon', os frutos são submetidos a préresfriamento em túneis, até atingirem a temperatura de polpa ideal para o armazenamento na câmara fria $\left(3^{\circ} \mathrm{C}\right)$, são então classificados, embalados e mantidos a esta temperatura até chegar ao consumidor. Já os melões Gália, Orange flesh e Charantais são pré-resfriados e armazenados à temperatura de $9^{\circ} \mathrm{C}$. Os melões Gália, Cantaloupe e o Charantais (para alguns produtores) utilizam atmosfera modificada (bolsas poliméricas Xtend ${ }^{\circledR}$ para cada cultivar) dentro das caixas, é embalado na câmara de pré-resfriamento e fechado somente após o resfriamento dos frutos, para evitar condensação de água. Também são utilizadas bandejas de papelão dentro das caixas que acondicionam os frutos para que não se toquem e para evitar ranhuras.

Após a embalagem, os frutos são etiquetados e recebem tratamento no pedúnculo, onde são aparados e pincelados com solução contendo cera natural e o fungicida Imazalil. As caixas também recebem o código de rastreabilidade e as identificações de tipo e variedade que contêm, depois são retiradas da esteira para a formação dos pallets.

O controle da temperatura e da umidade relativa durante o armazenamento refrigerado do melão é essencial para retardar o amadurecimento e prolongar a vida útil pós-colheita. Comercialmente, as principais empresas produtoras de melão do Polo Agrícola Mossoró-Assu/RN utilizam a chamada cadeia de frio, que consiste no pré-resfriamento como forma de baixar mais rapidamente a temperatura dos melões que vêm do campo, diminuindo assim seu calor vital e sua atividade respiratória. Em 
seguida, os frutos são armazenados em câmaras frias e mantidos até o embarque, que também é seguido de refrigeração até o local de consumo.

O transporte dos melões, que deve ser feito de acordo com as temperaturas recomendadas, seja em containers ou em carretas frigoríficas, deve ser monitorado para que não haja interrupções na cadeia de frio que vem sendo conduzida durante todo o processo, pois falha nesta etapa compromete a qualidade dos frutos. Entretanto, foi observado na presente pesquisa que ocorrem grandes oscilações de temperatura durante o armazenamento dos frutos no galpão de embalagem e durante todo o transporte (carretas e navios), oscilações estas suficientes para comprometer a qualidade dos frutos. No porto, existem câmaras de pré-resfriamento para resfriar os frutos que chegam com temperaturas acima da recomendada para cada variedade, e foi constatado que a maioria das cargas de melões chega ao porto com temperaturas superiores à recomendada, indicando que a cadeia de frio foi interrompida.

Os melões são enviados por via marítima pelos portos de Natal e do Pecém (Estado do Ceará). Os melões exportados pelo Porto de Natal são transportados em navios Reefers (porões refrigerados) e aqueles que são exportados pelo Porto de Pecém são enviados em conteiners refrigerados.

\subsection{Avaliação da qualidade dos frutos durante o armazenamento}

Na Tabela 1, podemos observar nos valores obtidos para os comprimentos longitudinal e transversal que os melões Orange flesh 'AF-1749' e Cantaloupe 'Torreon' apresentaram maior tamanho. Quanto à relação de formato, ficou bem próximo de 1,0 para todas as cultivares, indicando que os frutos têm formato arredondado. O melão Gália ‘Solar King' foi o que apresentou maior espessura da polpa.

Foi observada interação significativa para a aparência externa e interna em função do armazenamento (Figuras 1 e 2). A variação nas notas de aparência externa e interna foi caracterizada por um decréscimo gradativo, sendo mais acentuada para o melão Gália. No entanto, foi observado para todos os tipos de melões que aos 28 dias não apresentaram notas inferiores a 3,0. $\mathrm{O}$ que indica que estes frutos ainda estavam comercializáveis, apesar de terem atingido a nota limite que é 3,0 (11\% a 30\% da área externa do fruto apresentavam algum tipo de defeito). Pode-se verificar que alguns defeitos observados, tais como, manchas, depressões e injúrias, podem ser reduzidos com um manejo adequado dos frutos. Este período de 28 dias é o tempo requerido para o transporte marítimo e a comercialização na Europa. Mendonça et al. (2005) também verificaram que melões

Tabela 1. Caracterização dos tipos de melões nobres avaliados: Comprimento Longitudinal (CL); Comprimento Transversal (CT); Relação de Formato (RF) e Espessura da Polpa (EP).

\begin{tabular}{lcccc}
\hline \multicolumn{1}{c}{ Melão } & $\mathrm{CL}(\mathrm{cm})$ & $\mathrm{CT}(\mathrm{cm})$ & $\mathrm{RF}(\mathrm{cm})$ & $\mathrm{EP}(\mathrm{cm})$ \\
\hline Gália 'Solar King' & 13,9 & 13,78 & 1,01 & 4,29 \\
Cantaloupe 'Torreon' & 15,08 & 13,4 & 1,13 & 3,55 \\
Charentais 'Aura Prince' & 13,64 & 12,42 & 1,10 & 3,64 \\
Orange flesh AF-1749 & 15,1 & 14,01 & 1,08 & 3,60 \\
\hline
\end{tabular}

Orange flesh armazenados à temperatura ambiente tiveram uma vida útil de 21 dias, enquanto que os frutos mantidos a 5 e $7^{\circ} \mathrm{C}$ atingiram 28 dias com boa qualidade comercial.

Verificou-se uma variação significativa na perda de massa em função do tempo de armazenamento (Figura 3). Houve um aumento gradual da perda de massa ao longo do armazenamento para todos os tipos de melões estudados. No entanto, a perda de massa foi maior para o melão Orange Flesh que atingiu 5,56\% no final do armazenamento. Este resultado pode ser justificado pelo fato de que não foi utilizada a atmosfera modificada neste tipo de melão, enquanto que os demais foram armazenados em bolsas poliméricas Xtend ${ }^{\oplus}$ e tiveram uma perda de massa reduzida, constatando-se a eficiência desta embalagem na redução da perda de massa. Almeida (2002) também constatou uma redução na perda de massa de melão Cantaloupe 'Hy-Mark', e Lima et al. (2005) para melão Gália 'Solar King' submetido a bolsas poliméricas Xtend ${ }^{\circledR}$.

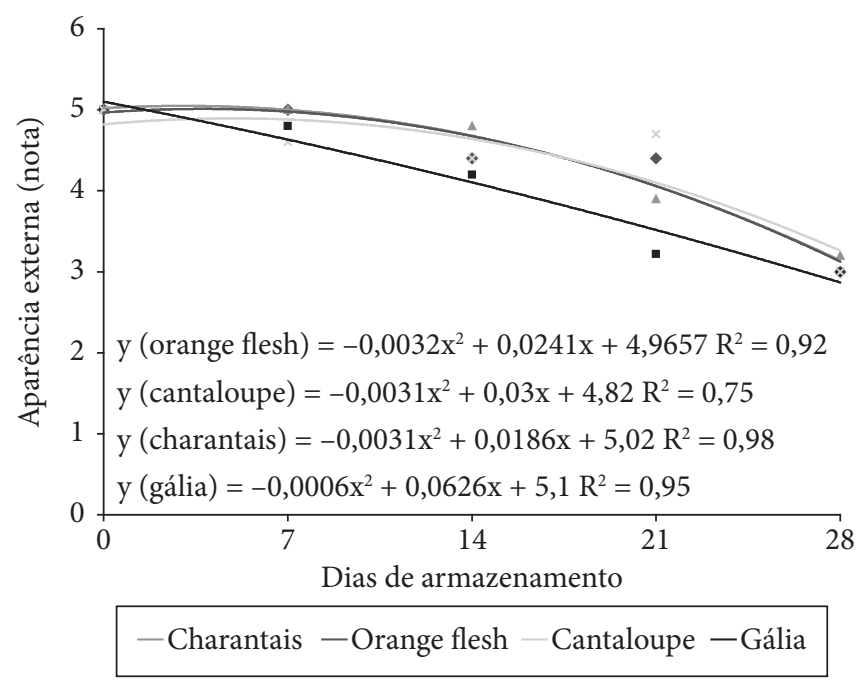

Figura 1. Aparência externa de melões nobres durante o armazenamento refrigerado.

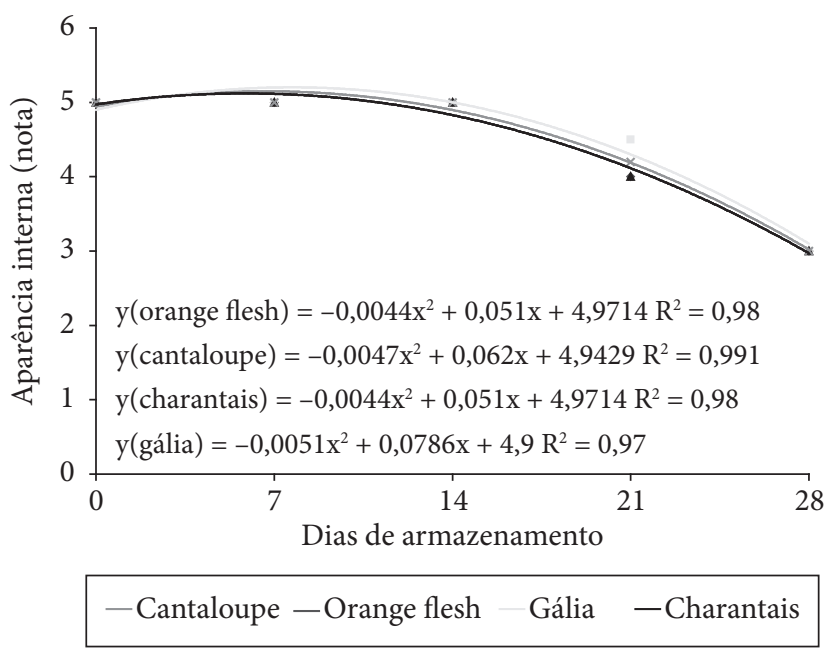

Figura 2. Aparência interna de melões nobres durante o armazenamento refrigerado. 
A firmeza da polpa teve um decréscimo gradual e significativo ao longo do período de armazenamento para todos os tipos de melões avaliados (Figura 4). No dia da colheita, os valores de firmeza foram 41,09, 45,67 e 50,53 N, 45,67 N para os melões Gália, Cantaloupe, Orange Flesh e Charentais, respectivamente. Os melões apresentaram elevados valores de firmeza, quando comparados com as exigências dos mercados exportadores, pois Alves et al. (2000) relatam que, para cumprir as exigências dos mercados exportadores, a firmeza recomendada é de $30 \mathrm{~N}$, no momento da colheita do melão. Os resultados aqui encontrados indicam que os frutos foram colhidos ainda imaturos.

As variações nos teores de acidez titulável ao longo do armazenamento foram pequenas. Para o melão Charentais, esta diferença não foi significativa, mas o foi para os demais tipos (Figura 5). No final do armazenamento, houve uma tendência à redução para todos os tipos de melões estudados.

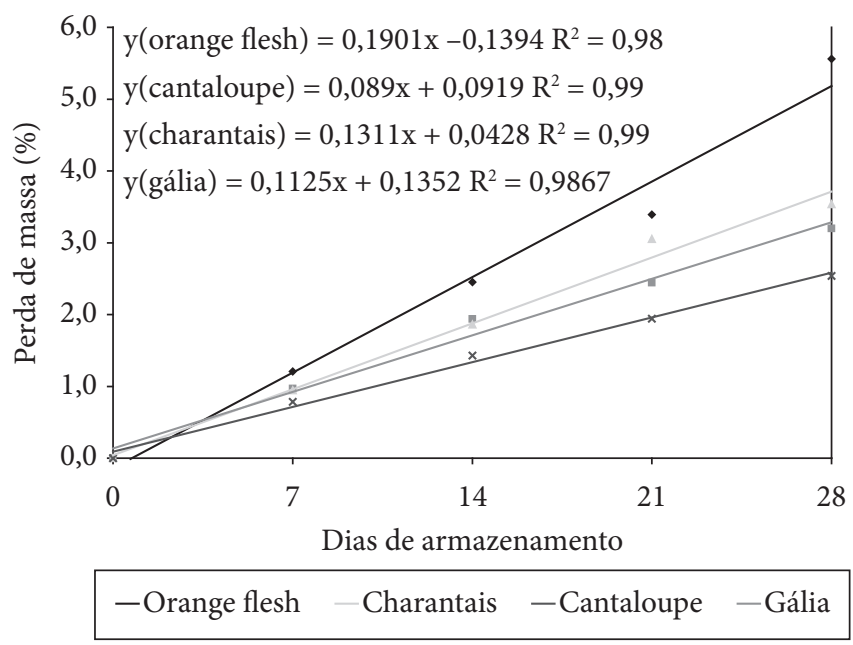

Figura 3. Perda de massa de melões nobres durante o armazenamento refrigerado.

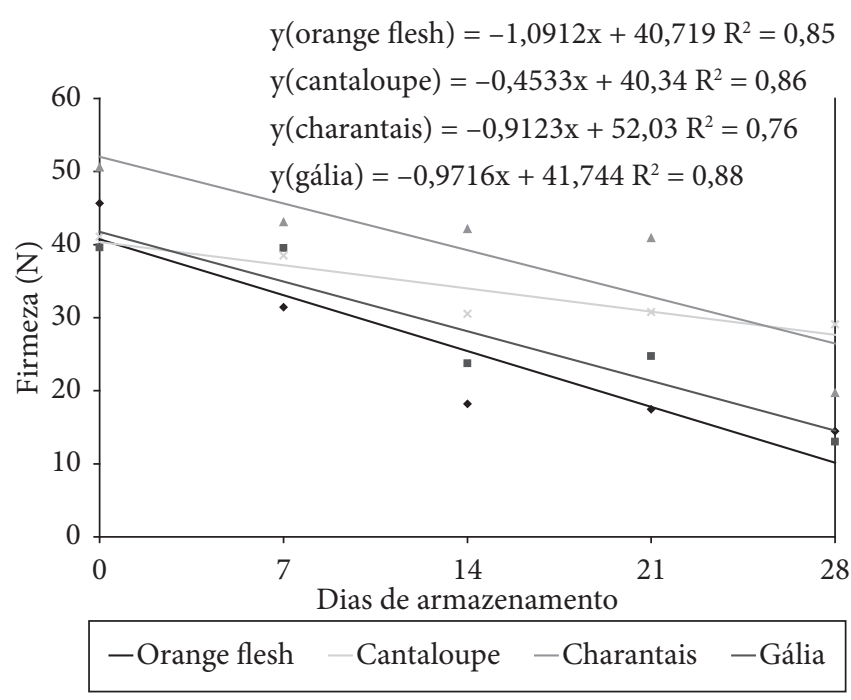

Figura 4. Firmeza de polpa de melões nobres durante o armazenamento refrigerado.
Na maioria dos frutos, a acidez representa um dos principais componentes do flavor, pois sua aceitação depende do balanço entre ácidos e açúcares, sendo que a preferência incide sobre altos teores desses constituintes. No melão, a variação nos níveis de acidez tem pouco significado em função da baixa concentração, e a intervenção da acidez no sabor não é muito representativa.

As variações no $\mathrm{pH}$ também foram pequenas para todos os tipos estudados, apesar de ter dado significativo, com exceção do tipo amarelo em que não foi significativa esta diferença (Figura 6). Isto pode ser explicado pela capacidade tamponante dos sucos de frutas, podendo ocorrer variações na AT, sem variações apreciáveis no pH (CHITARRA; CHITARRA, 2005).

Não houve diferença significativa nos teores de sólidos solúveis e açúcares solúveis durante o armazenamento para todos os tipos de melões estudados. Na Tabela 2, podem-se observar os valores médios obtidos para cada tipo de melão. Quando comparado com as exigências do mercado exportador, segundo Alves et al (2000), estes valores estão abaixo dos recomendados

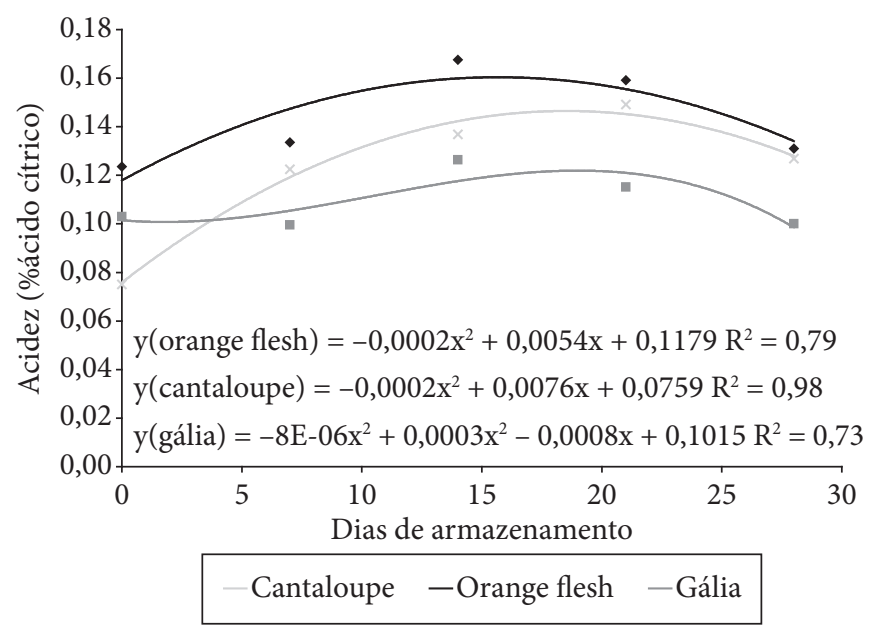

Figura 5. Acidez titulável de melões nobres durante o armazenamento refrigerado.

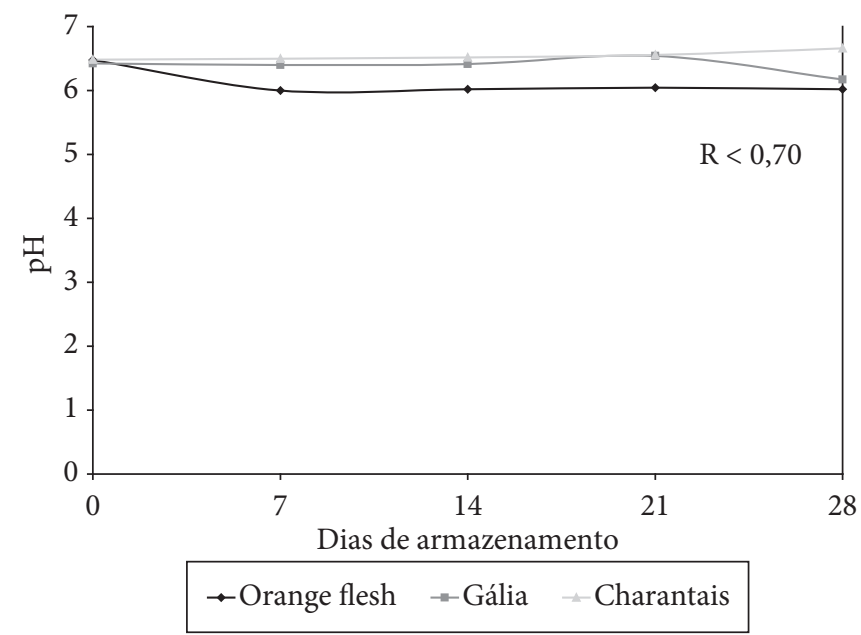

Figura 6. pH de melões nobres durante o armazenamento refrigerado. 
Tabela 2. Teores médios de sólidos solúveis e açúcares de melões nobres submetidos ao armazenamento refrigerado.

\begin{tabular}{lcc}
\hline \multicolumn{1}{c}{ Tipo de melão } & $\begin{array}{c}\text { Sólidos } \\
\text { solúveis }\left({ }^{\circ} \mathrm{Brix}\right)\end{array}$ & $\begin{array}{c}\text { Açúcares totais } \\
\left(\mathrm{g} .100 \mathrm{~g}^{-1}\right)\end{array}$ \\
\hline Gália 'Solar King' & 9,4 & 7,7 \\
Cantaloupe 'Torreon' & 8,9 & 7,2 \\
Charentais 'Aura Prince' & 10,8 & 8,7 \\
Orange flesh 'AF-1749' & 9,1 & 7,5 \\
\hline
\end{tabular}

que são de $12 ; 10 ; 13$; e $10^{\circ}$ Brix no mínimo, para os melões tipo Gália, Cantaloupe, Charetais e Orange Flesh, respectivamente. Estes resultados concordam com os valores observados para firmeza e constatam que são colhidos frutos em estádio de maturação inadequado, ou seja, ainda imaturo. A colheita em estádio de maturação inadequado é um grande erro, pois um ponto de colheita adequado é essencial para a qualidade dos frutos. Os produtores devem ficar mais atentos a uma das principais etapas determinante da qualidade dos frutos.

\section{Conclusões}

As empresas produtoras e exportadoras de melões nobres utilizam um alto nível de tecnologias pós-colheita para manter a qualidade dos frutos dessas cultivares que apresentam pouca resistência pós-colheita. No entanto, foi constatado, pelos baixos valores de firmeza e sólidos solúveis observados, que são colhidos frutos imaturos; e, ainda, que os frutos são manuseados de forma inadequada, provocando o aparecimento de manchas, depressões e injúrias.

A utilização de bolsas poliméricas Xtend ${ }^{\circledR}$ nos melões Gália 'Solar King', Cantaloupe 'Torreon' e Charantais 'Aura Prince' é eficiente na redução da perda de massa.

\section{Referências bibliográficas}

ALBUQUERQUE, V. Fruticultura-RN quer novos mercados para frutas. Noticias Agropecuárias. Disponível em: <http:// agroinformacao.blogspot.com/2008/06/fruticultura-rn-quernovos-mercados.html>. Acesso em: 20 Ago. 2008.

ALVES, R. E. et al. Manual de melão para exportação. Brasília, DF: Embrapa, 2000. 51 p.

ALMEIDA, A. S. Conservação de melão Cantaloupe "Hy-Mark" tratados com 1-MCP após a colheita. Mossoró, 2002. 143 p. Tese (Mestrado) - Universidade Federal Rural do Semi-Árido - UFERSA.

ASSOCIATION OF OFFICIAL ANALYTICAL CHEMISTRY AOAC. Official methods of analysis of the Association of Official Analytical Chemistry. 17 ed. Washington, 2002. 1115p.

CHITARRA, M. I. F.; CHITARRA, A. B. Pós-colheita de frutas e hortaliças: fisiologia e manejo. 2 ed. Lavras: Ufla, 2005. 785p.

INSTITUTO ADOLFO LUTZ. Normas analíticas, métodos químicos e físicos para análise de alimentos. 3 ed. São Paulo, 1985. v. 1, $533 \mathrm{p}$.

LIMA, M. A. C. et al. Qualidade pós-colheita de melão Gália submetido a modificação da atmosfera e ao 1- metilciclopropeno. Horticultura Brasileira, v. 23, n. 3, p. 793 -798, 2005.

MENDONÇA, F. V. de S. et al. Armazenamento refrigerado de melão Orange Flesh. Horticultura Brasileira, v. 23, n. 1, p. 15-18, 2005.

MENEZES, J. B. Qualidade pós-colheita de melãotipo Galia durante a maturação e o armazenamento. Lavras,1996. 157 p. Tese (Doutorado) - Universidade Federal de Lavras - UFLA.

MOURA, W. B. D. Qualidade do melão (Cucumis melo L.) exportado pelo porto de Natal-RN no período de setembro a novembro de 2003. Mossoró, 2003. 48p. Monografia (Graduação) - Escola Superior de Agricultura de Mossoró - ESAM.

YEMN, E. W.; WILLIS, A. J. The estimation of carbohydrate in plant extracts by anthrone. The Biochemical Journal, v. 57, p. 508-514, 1954. 